\title{
Development of a Traveling Wave Superconducting Accelerating Structure
}

\author{
Cooperative Research and Development Agreement \\ Final Report
}

CRADA Number: FRA-2007-0001E

Fermilab Technical Contact: Victor Yarba

Summary Report

Updated June 2010 


\section{NOTICE}

This report was prepared as an account of work sponsored by an agency of the United States government. Neither the United States government nor any agency thereof, nor any of their employees, makes any warranty, express or implied, or assumes any legal liability or responsibility for the accuracy, completeness, or usefulness of any information, apparatus, product, or process disclosed, or represents that its use would not infringe privately owned rights. Reference herein to any specific commercial product, process, or service by trade name, trademark, manufacturer, or otherwise does not necessarily constitute or imply its endorsement, recommendation, or favoring by the United States government or any agency thereof. The views and opinions of authors expressed herein do not necessarily state or reflect those of the United States government or any agency thereof.

Available electronically at http://www.osti.gov/bridge

Available for a processing fee to U.S. Department of Energy and its contractors, in paper, from: U.S. Department of Energy Office of Scientific and Technical Information P.O. Box 62

Oak Ridge, TN 37831-0062

phone: 865.576.8401

fax: 865.576.5728

email: mailto:reports@adonis.osti.gov

Available for sale to the public, in paper, from:

U.S. Department of Commerce

National Technical Information Service

5285 Port Royal Road

Springfield, VA 22161

phone: 800.553.6847

fax: 703.605.6900

email: orders@ntis.fedworld.gov

online ordering: http://www.ntis.gov/ordering.htm 
In accordance with Requirements set forth in Article XI.A(3) of the CRADA document, this document is the final CRADA report, including a list of Subject Inventions, to be forwarded to the Office of Science and Technical Information as part of the commitment to the public to demonstrate results of federally funded research.

CRADA number: $\quad$ FRA-2007-0001 (Euclid)

CRADA Title: $\quad$ Development of a Traveling Wave Accelerating Structure for a Superconducting Accelerator

Parties to the Agreement: Euclid Techlabs, LLC and Fermi Research Alliance, LLC

\begin{abstract}
CRADA work:
The primary goal of Phase I is a baseline conceptual design of a STWA structure. Work includes simulation and optimization of a L-band Superconducting TWA cavity with respect to magnetic and electrical surface field rations, inter-cell coupling coefficients, and accelerating field flatness. The primary goal of Phase I is a baseline conceptual design of a STWA structure. Work includes simulation and optimization of a L-band Superconducting TWA cavity with respect to magnetic and electrical surface field rations, inter-cell coupling coefficients, and accelerating field flatness. The main objective of the Phase II project is to perform a proof-ofprinciple experiment to demonstrate the feasibility of the SC traveling wave accelerating (STWA) structure Supported in part by DOE SBIR grant application DE-FG02-06ER844464.
\end{abstract}

\title{
Summary of Research Results:
}

In Phase I of the project, a conceptual design of the SC TW accelerating structure was developed and mathematically simulated.

In Phase II of the project, we carried out high gradient operation and conducted RF field measurements for a single-cell cavity that incorporates a feedback waveguide. Specific tasks included:

- refinement of the single-cell cavity and feedback waveguide electrical parameters

- conceptual design of the single-cell cavity with feedback waveguide.

- engineering design of the single test cavity

- two single-cell test cavities have been fabricated

- full surface processing of a single test cavity with feedback at the Argonne/Fermilab SC surface processing facility

- theoretical analysis and computer modeling for: (a) tuning parameters; (b) HOM damping; (c) high-power input and (d) beam loading issues

- Completed two high gradient tests of the developed single test cavities at the Fermilab vertical cryomodule 
The high gradient tests have been carried out to establish a baseline for characterization of the SC Traveling Wave methods and technology and validate the suitability of the SC TW accelerating structure concept for potential ILC applications.

- The test of the cavity N2 after BCP showed a quench at a surface field of $~ 93-95 \mathrm{mT}$ that corresponds to the acceleration gradient of $\sim 31 \mathrm{MeV} / \mathrm{m}$ for the TW cavity.

- TW cavity N2 sustains higher surface electric fields than other SW cavities.

- No strong field emissions were observed.

- Multipactoring in the waveguide doesn't limit the gradient.

- The waveguide mode has a quench at $120 \mathrm{mT}$ that is significantly higher than those for the operating mode. Multipactoring was easily passed.

- Q-factors were found to be relatively low in these tests. Additional surface processing and optical surface inspection are required for improving the quality factor. Existing infrastructure at Fermilab may not provide optimal control of process parameters (acid temperature and flow).

- High field Q slopes have not been observed up to $95 \mathrm{mT}$ and $58 \mathrm{MV} / \mathrm{m}$ surface fields at $\mathrm{N} 2$ tests.

The proposed STWA structure has crucial advantages in comparison with the standing wave designs (SW) like the recently developed Re-Entrant cavity that in turn has significant advantages over the 9-cell TESLA cavity. This advantage is an increased accelerating gradient to up to a factor 1.24 while maintaining the same the Re-Entrant cavity magnetic and electrical surface field ratios $E_{\text {peac }} /$ Eacc $_{\text {and }} B_{\text {peak }} /$ Eacc.

Furthermore, the proposed SC TW acceleration method will provide accelerating parameters that allow much longer accelerating structures to be built that are also critical for the effective gradient enhancement. The length of the SW accelerating structure is limited by the strong sensitivity of the field flatness along the structure to the dimension errors. The proposed TW structure does not have this strong limitation. If manufacturing and surface processing technology allow, the STWA structure gives the possibility in principle of considering a $10 \mathrm{~m}$ long STWA section that is limited only by the cryomodule length. This means that the effective accelerating gradient if a TW structure is employed can be increased by $22 \%$, giving an overall $46 \%$ gain over the SW ILC structure. The proposed modification will result in a total accelerating structure length reduction in a factor of 1.46. In general, this proposed scheme based on a high gradient STWA cavity will allow higher accelerating gradients that are the main goal of the superconducting accelerating community.

The project has demonstrated of the feasibility of the proposed concepts in mechanical manufacturing, assembly and welding of the proposed STWA structure shape. The surface processing issues have been resolved, which is a customary procedure for the SC cavity technology. The single cell SC traveling wave structure has been developed and standing wave measurements of the surface field ratios were done, demonstrating that the surface magnetic field is nearly comparable to the similarly processed (BCP) TESLA-shaped single cells. Experimental rf testing demonstrated the high gradient potential of the proposed design. 
These results open the way for the next step in TW SC cavity development: to build and test a traveling-wave three-cell cavity with a feedback waveguide. The overall objectives of this project would be investigation of the 3-cell SC traveling wave accelerating structure's feasibility and experimental demonstration of its tuning performance and backward wave damping capabilities.

\section{Related Reports, Publications, and Presentations:}

1. Kanareykin, Alex. DEVELOPMENT OF A TRAVELING WAVE ACCELERATING STRUCTURE FOR A SUPERCONDUCTING ACCELERATOR. United States: N. p., 2011. Web. (OSTI Identifier 1004770)

2. V. Avrakhov, A. Kanareykin, S. Kazakov, N. Solyak, V. P. Yakovlev. Progress Towards Development of a Superconducting Traveling Wave Accelerating Structure. Proceedings Particle Accelerator Conference PAC2007, Albuquerque, NM, pp. 2182-2184, 2007.

3. A. Kanareykin, P. V. Avrakhov, Z. Liu, W. Gai, S. Kazakov, N. Solyak, V. P. Yakovlev. Conceptual Design of an L-Band Recirculating Superconducting Traveling Wave Accelerating Structure. Proceedings Particle Accelerator Conference PAC2007, Albuquerque, NM, pp. 2538-2540, 2007.

4. A.Kanareykin et al. Talk at SRF Seminar, Cornell University, November 2007. www.euclidtechlabs.com

5. A. Kanareykin, P. Avrakhov, S. Kazakov, N. Solyak, V. Yakovlev. Progress Towards Development of an L-Band SC Traveling Wave Accelerating Structure with Feedback. Proceedings EPAC 2008, Genova, Italy, June 2008, pp. 871-873, 2008.

6. P. Avrakhov, A. Kanareykin, S. Kazakov, N. Solyak, and V. Yakovlev "Development of a High Gradient SC Traveling Wave Accelerating Cavity ". Physics of Particles and Nuclei Letters, 2008, Vol. 5, No. 7, pp. 597-600.

7. A.Kanareykin, V.P.Yakovlev, P.Avrakhov, S.Kazakov, N.Solyak. An L-Band Superconducting Traveling Wave Accelerating Structure With Feedback. 13th Advanced Accelerator Concept Workshop AAC-2008, AIP Conference Proceedings, New York, American Institute of Physics, v. 1086, pp.445-451, 2008.

8. V. P. Yakovlev, A. Lunin, N. Solyak, P. V. Avrakhov, A. Kanareykin, S. Kazakov. Excitation of Traveling Wave in a Superconducting Structure with Feedback. Proceedings Particle Accelerator Conference PAC’09, Vancouver, Canada, pp. 969-971, 2009. 
9. G. Wu, M. Ge, I.Gonin, T.Khabiboulline, J. Ozelis, A.Rowe, N.Solyak, V.Yakovlev, J. Rathke, P.V. Avrakhov and A. Kanareykin . First High-gradient Tests of the Single-cell SC Cavity with the Feedback Waveguide. Proceedings International Particle Accelerator Conference IPAC'10, Kyoto, Japan, pp. 4390-4392, 2010.

10. V. Yakovlev, N. Solyak, G. Wu, M. Ge, I. Gonin, T. Khabiboulline, J. Ozelis, A. Rowe, P. Avrakhov, A. Kanareykin, and J. Rathke. High-Gradient Tests of the Single-Cell SC Cavity with a Feedback Waveguide. 14th Advanced Accelerator Concept Workshop AAC-2010, AIP Conference Proceedings, New York, American Institute of Physics, v. 1299, Annapolis, (Maryland), 13-19 June 2010, pp. 313-318, 2010.

\section{Subject Inventions listing:}

None

Report Date: June 2010

Technical Contact at Fermilab: Victor Yarba

This document contains NO confidential, protectable or proprietary information. 